\title{
DNA functionalization by dynamic chemistry
}

\author{
Zeynep Kanlidere, Oleg Jochim, Marta Cal and Ulf Diederichsen
}

\section{Full Research Paper}

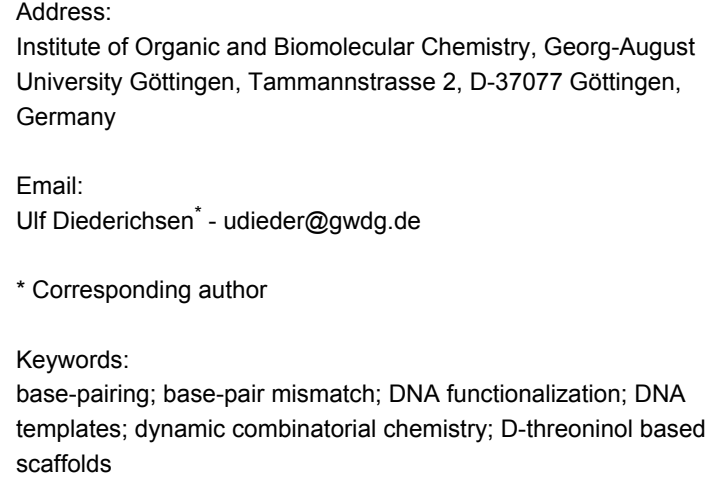

Beilstein J. Org. Chem. 2016, 12, 2136-2144.

doi:10.3762/bjoc. 12.203

Received: 03 June 2016

Accepted: 08 August 2016

Published: 06 October 2016

Associate Editor: S. Flitsch

(C) 2016 Kanlidere et al.; licensee Beilstein-Institut. License and terms: see end of document.

\begin{abstract}
Dynamic combinatorial chemistry (DCC) is an attractive method to efficiently generate libraries of molecules from simpler building blocks by reversible reactions under thermodynamic control. Here we focus on the chemical modification of DNA oligonucleotides with acyclic diol linkers and demonstrate their potential for the deoxyribonucleic acid functionalization and generation of libraries of reversibly interconverting building blocks. The syntheses of phosphoramidite building blocks derived from D-threoninol are presented in two variants with protected amino or thiol groups. The threoninol building blocks were successfully incorporated via automated solid-phase synthesis into 13 mer oligonucleotides. The amino group containing phosphoramidite was used together with complementary single-strand DNA templates that influenced the Watson-Crick base-pairing equilibrium in the mixture with a set of aldehyde modified nucleobases. A significant fraction of all possible base-pair mismatches was obtained, whereas, the highest selectivity (over $80 \%$ ) was found for the guanine aldehyde templated by the complementary cytosine containing DNA. The elevated occurrence of mismatches can be explained by increased backbone plasticity derived from the linear threoninol building block as a cyclic deoxyribose analogue.
\end{abstract}

\section{Introduction}

The well-defined duplex structure, self-assembling by base-pair recognition, and the accessibility by solid-phase synthesis make DNA oligonucleotides an ideal supramolecular scaffold in a wide field of applications [1,2]. In recent years oligonucleotides especially were applied to self-assembly into artificial nanostructures [3-9]. Preparation of oligonucleotides for new applications requires the introduction of additional functional groups into its native structure [10,11]. Such chemically modified oligonucleotides are useful intermediates for their subsequent functionalization through post-synthetic protocols [1113]. Within a post-synthetic strategy, a nucleotide analog is modified with a reactive functional group, incorporated into 
oligonucleotides by standard solid-phase synthesis and reacted with the desired molecules on the oligonucleotide level. As amines and thiols are among the widely used groups introduced for the post-synthetic modifications, the acyclic threoninol linker (2-amino-1,3-butanediol) [14-21] constitutes an attractive choice for oligonucleotide functionalization. Threoninol can be introduced in oligonucleotides via the corresponding phosphoramidite generating a ribose-free abasic site on the backbone that provides the amine group for later functionalization [22-28]. Similarly, a thiol functionality can be introduced by substitution of the amine group of threoninol and incorporated into the oligonucleotide backbone. The amine and thiol groups can be used for further oligonucleotide functionalization reacting these sites with functional molecules like metal ligands or fluorophores. Functional molecules of interest can be tethered post-synthetically in an irreversible manner as amide or reversibly as imine or thioester.

Recent advances in dynamic combinatorial chemistry [29-40] have enabled the utilization of presynthesized oligomers with abasic sites on the backbone for the addition of individual monomeric nucleobases and consider the synthesis of new oligonucleotide analogues possessing different backbone topologies [41]. Ghadiri et al. employed this approach for an enzyme-free synthesis of an oligonucleotide analogue with a peptide backbone carrying nucleobases on its amino acid side chains [42] while Bradley et al. used the backbone of a peptide nucleic acid (PNA) with abasic sites which gives a reactive secondary amine for reversible attachment of aldehyde modified nucleobases [43]. Moreover, the DNA template-directed selection of one nucleobase from the reaction mixture with the amine or thiol functional group was investigated [44-47].

In our studies, dynamic chemistry is applied for post-synthetic functionalization of the threoninol based modified oligonucleotides in a reversible manner. Here we synthesized the phosphoramidite building blocks derived from D-threoninol which contain protected amine or thiol groups. These building blocks are used for later incorporation into oligonucleotides via solidphase synthesis. Using these modified oligonucleotides and single strand DNA templates, we generated the libraries of reversibly interconverting building blocks - dynamic combinatorial libraries (DCL) (Figure 1). The abasic strand and its complementary template strand are spontaneously assembled into a double helix through Watson-Crick base-pairing and the incoming nucleobase monomer benefits from the hydrogen bonding recognition by the respective nucleobase in the template strand. The reversible attachment generates a dynamic system that enables the combinatorial screening of the best bound nucleobase by allowing a rapid and continuous exchange between the threoninol site and the set of nucleobase monomers.
In case of an amine group on the backbone, a reversible imine exchange reaction with aldehyde modified nucleobases was performed (Figure 1a). In the presence of a thiol group on the backbone, a thioester exchange reaction with thioester modified nucleobases was expected (Figure 1b).

\section{Results and Discussion D-Threoninol-based building blocks: design and synthesis}

Two D-threoninol-based phosphoramidite building blocks containing orthogonally protected amine 4 or thiol 11 moieties were successfully synthesized. As presented in Scheme 1 phosphoramidite 4 was obtained according to the procedures previously described in literature [14,23].

In order to obtain phosphoramidite $\mathbf{1 1}$ we have developed a synthesis (Scheme 2) based on L-threonine as a starting material. L-Threonine was converted to bromo-derivative 6 by a diazotization reaction using sodium nitrite followed by potassium bromide substitution under overall retention of configuration due to double inversion. Next, the subsequent reduction of carboxylic acid 6 to alcohol 7 was achieved by borane dimethyl sulfide (BMS) under dry conditions. The reaction between alcohol 7 and 3-mercaptopropanenitrile (8) resulted in substitution of bromine to the thiol group and finally the introduction of the thiol functional group. The 3-mercaptopropanenitrile (8) was synthesized separately in two steps from acrylonitrile or the 3 -chloropropanenitrile according to the previously described procedure [48-50]. Next, the obtained compound 9 containing two hydroxy groups and the cyanoethyl protected thiol group was converted into the phosphoramidite being compatible with conditions of solid-phase oligonucleotide synthesis. The DMTr protecting group was incorporated and the conversion of the secondary alcohol $\mathbf{1 0}$ to phosphoramidite $\mathbf{1 1}$ was performed. The base-labile cyanoethyl group [51,52] is known to be resistant under synthesis conditions for the preparation of the phosphoramidite building block and for solid-phase oligonucleotide synthesis $[49,53]$.

\section{Building blocks compatibility with solid-phase synthesis of DNA single strands}

Phosphoramidites $\mathbf{4}$ and $\mathbf{1 1}$ were introduced at position seven of 13mer oligonucleotides ON1 and ON2 applying automated solid-phase synthesis (Table 1 and Supporting Information File 1, Table S1). The last step in the oligonucleotide synthesis involved the deprotection of the amine group using ammonium hydroxide at $55^{\circ} \mathrm{C}$. The Fmoc protecting group of oligonucleotide ON1 was removed, however, the cyanoethyl group as a base-labile protecting group of the thiol was not removed quantitatively from the oligonucleotide ON2 [54-58]. 

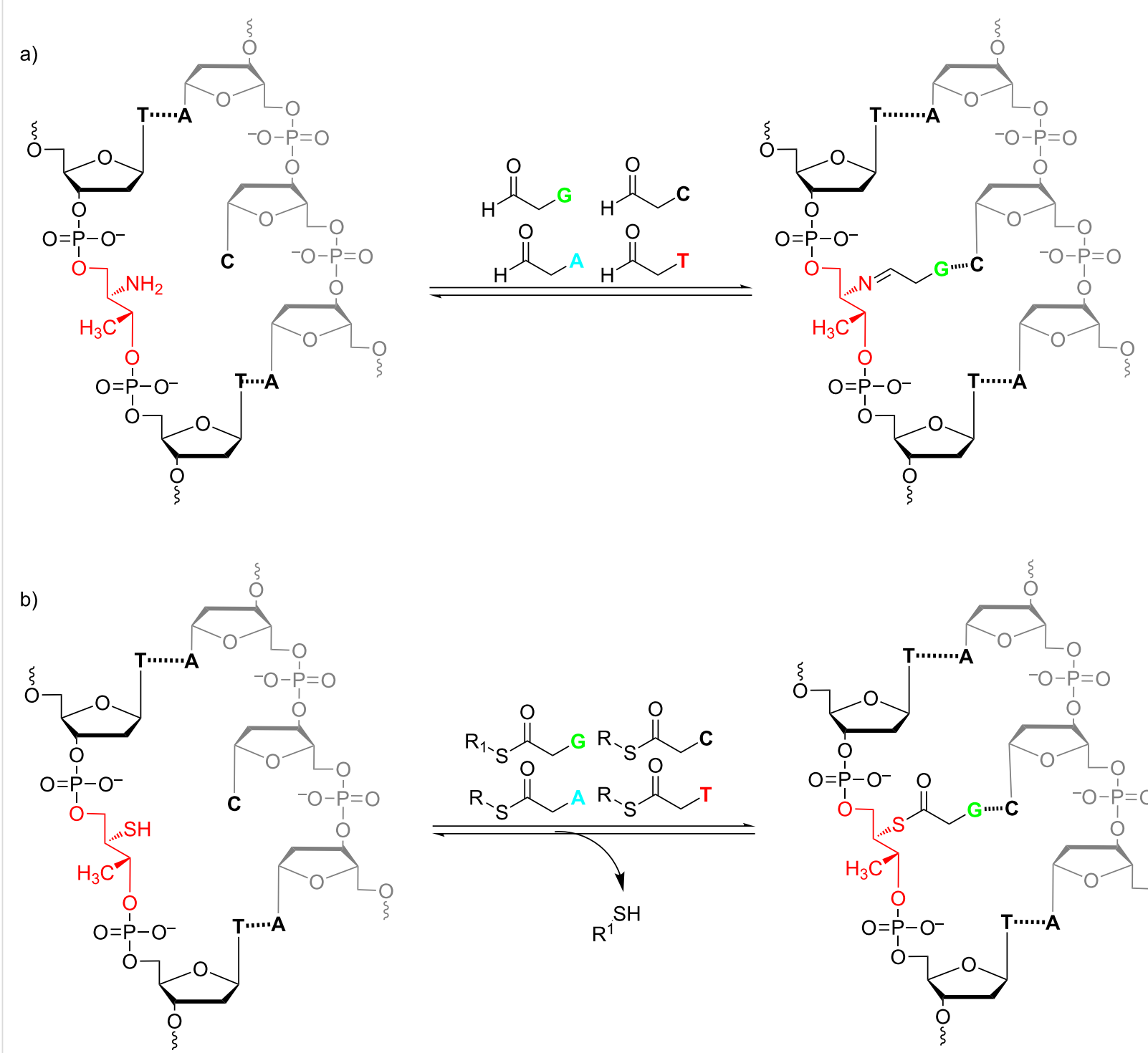

Figure 1: Template-directed dynamic chemistry assay for the attachment of modified nucleobase monomers to an abasic backbone. a) Reversible imine exchange reaction. b) Reversible thioester exchange reaction.

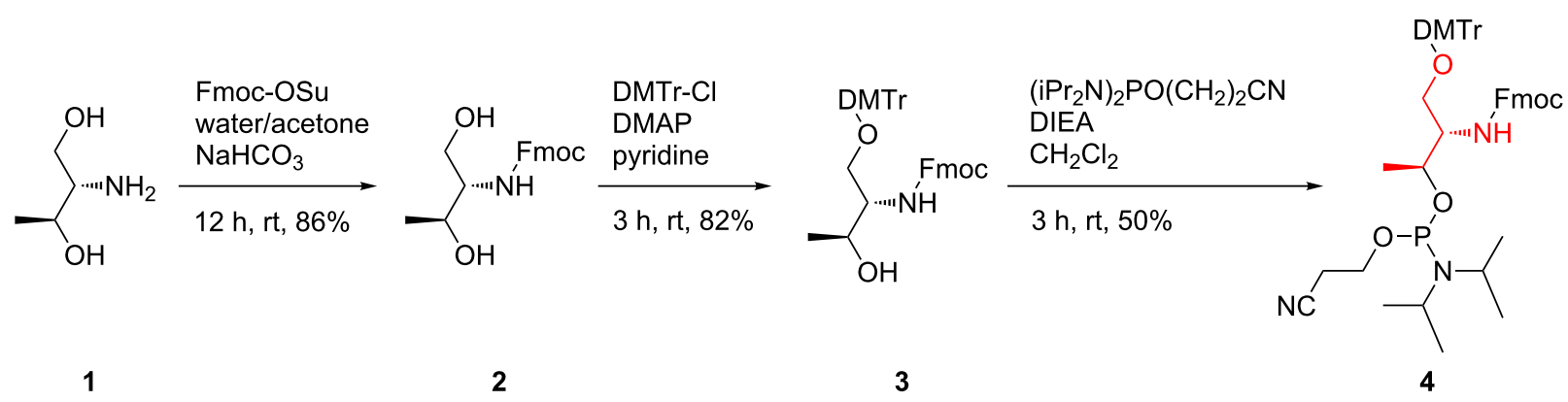

Scheme 1: Synthesis of the phosphoramidite building block 4 [23]. DMTr: dimethoxytrityl group, Fmoc: 9-fluorenylmethylcarbonyl, DMAP: 4-dimethylaminopyridine, DIEA: $\mathrm{N}, \mathrm{N}$-diisopropylethylamine. 


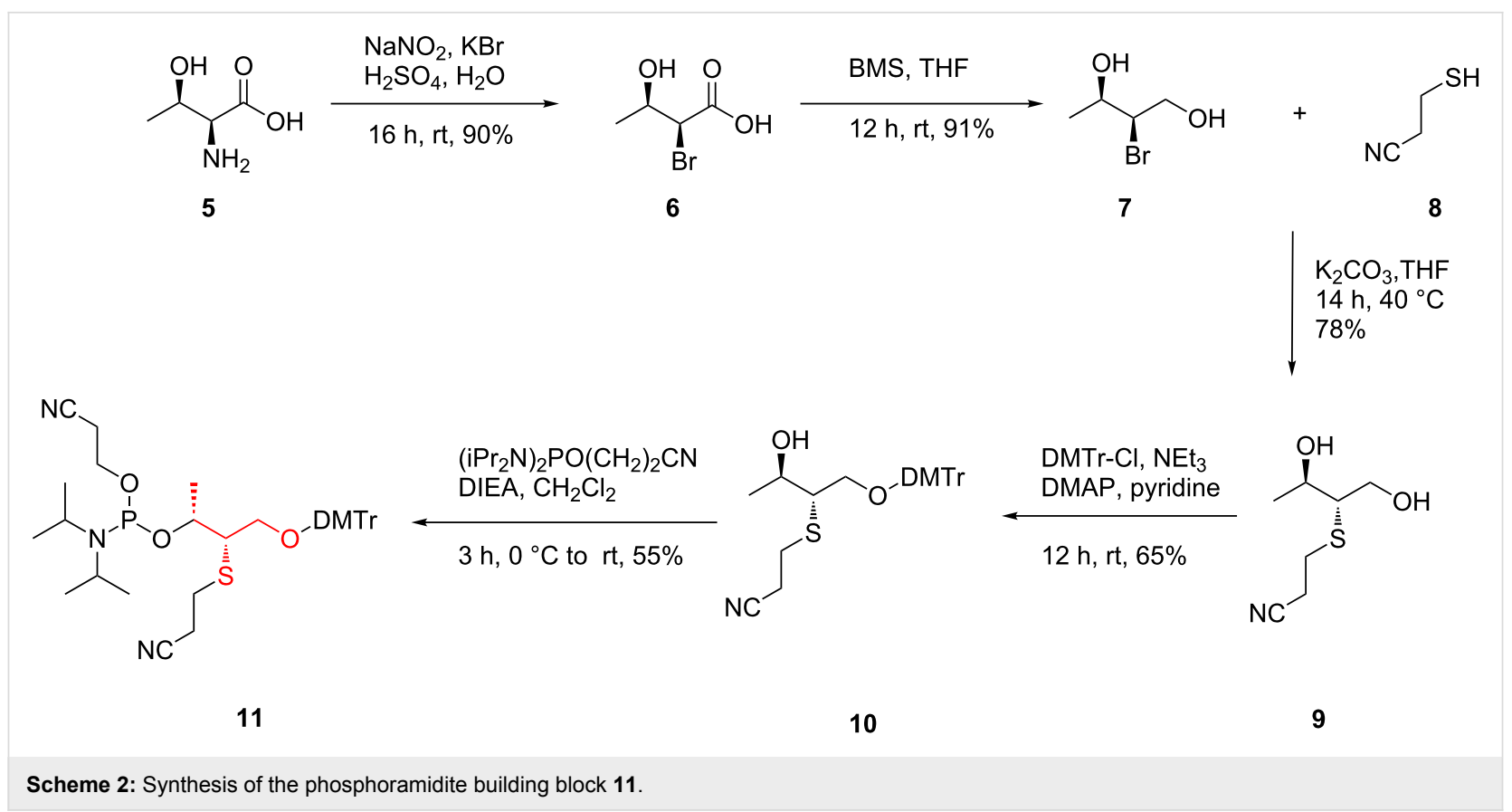

\begin{tabular}{ll}
$\begin{array}{l}\text { Table 1: Sequences of modified oligonucleotide and templates used in } \\
\text { this work. }\end{array}$ \\
Strand & Sequence (5'-3') \\
\hline ON1 & CGCTATXTATCGC ${ }^{a}$ \\
ON2 & GCGATAYATAGCG \\
$\mathbf{T}_{\mathbf{C}^{b}}$ & GCGATACATAGCGGTT \\
$\mathbf{T}_{\mathbf{G}}{ }^{\mathrm{b}}$ & GCGATAGATAGCGGTT \\
$\mathbf{T}_{\mathbf{T}}{ }^{\mathrm{b}}$ & GCGATATATAGCGGTT \\
$\mathbf{T}_{\mathbf{A}}{ }^{\mathrm{b}}$ & GCGATAAATAGCGGTT \\
\hline
\end{tabular}

${ }^{a} \mathbf{X}$ and $\mathbf{Y}$ represent the abasic site with amino or thiol group, respectively. ${ }^{b}$ Here, the capital letter index of $\mathbf{T}$ stands for the cytosine, guanine, thymine or adenine nucleobase positioning opposite to the amine on ON1. 'Nucleobases that are opposite to the abasic site of the modified strand are shown in bold letters. The GTT sequence at the 3'-terminus was added to facilitate separation by HPLC.

\section{Dynamic template-driven assembly of double strand libraries}

Oligonucleotide ON1 was used for further investigations towards dynamic libraries of double strand DNA constructs. Oligonucleotide ON1 was used with the deprotected amine group in the reaction of forming the imine bond between $\mathrm{ON} 1$ and four nucleobase aldehydes $\left(\mathbf{G}_{\mathbf{C H O}}, \mathbf{C}_{\mathbf{C H O}}, \mathbf{A}_{\mathbf{C H O}}, \mathbf{T}_{\mathbf{C H O}}\right)$ in the presence of complementary template strands $\mathbf{T}_{\mathbf{C}}, \mathbf{T}_{\mathbf{G}}, \mathbf{T}_{\mathbf{T}}$ or $\mathbf{T}_{\mathbf{A}}$ (Table 1). The respective template strand should control the incorporation of the corresponding nucleobase reversibly linked as imine (Figure 2). The structures of four nucleobase aldehydes were shown in Figure 3. These compounds were synthesized according to the procedures described previously [59-61].
At the beginning we determined the conversion of ON1 with the respective nucleobase aldehydes in presence of the complementary DNA template strand (Table 1). The ON1 oligonucleotide was allowed to react with only one nucleobase in order to produce the individual product (Supporting Information File 1, Figure S1, Table S2). A reaction between $\mathbf{G}_{\mathbf{C H O}}$ and $\mathbf{O N 1}$ in the presence of $\mathbf{T}_{\mathbf{C}}$ was accomplished with complete conversion of ON1 into the guanine incorporated product $(\mathbf{O N 1}+\mathbf{G})$. The reactions with cytosine $\left(\mathbf{C}_{\mathbf{C H O}}\right)$ as well as adenine $\left(\mathbf{A}_{\mathbf{C H O}}\right)$ aldehydes gave similar yields, however, with lower conversion level of ON1 compared to the previous case. Finally, lowest conversion was observed for the reaction of $\mathbf{O N} \mathbf{1}$ with the $\mathbf{T}_{\mathbf{A}}$ template and the thymine aldehyde $\left(\mathbf{T}_{\mathbf{C H O}}\right)$ (Supporting Information File 1, Table S3).

\section{The composition of libraries: base-pairing selectivity}

To determine the influence of the DNA template on nucleobase incorporation into the strands at abasic site through imine attachment to the amine group, four reactions were carried out under identical conditions ( $\mathrm{pH} \mathrm{6,20} \mathrm{mM} \mathrm{phosphate} \mathrm{buffer),} \mathrm{but}$ differing in the applied template strand. The 13 mer oligonucleotide ON1 was mixed with one of the four complementary template strands $\left(\mathbf{T}_{\mathbf{C}}, \mathbf{T}_{\mathbf{G}}, \mathbf{T}_{\mathbf{T}}\right.$ or $\mathbf{T}_{\mathbf{A}}$, Table 1) in a 1:1 molar ratio. All four nucleobase aldehydes $\left(\mathbf{G}_{\mathbf{C H O}}, \mathbf{C}_{\mathbf{C H O}}, \mathbf{A}_{\mathbf{C H O}}, \mathbf{T}_{\mathbf{C H O}}\right)$ were added in excess amount and in equimolar concentrations.

Sodium cyanoborohydride $\left(\mathrm{NaBH}_{3} \mathrm{CN}\right)$ was used for irreversible conversion of the imine products obtained in equilibrium into respective amines (Figure 2), thereby enabling the 


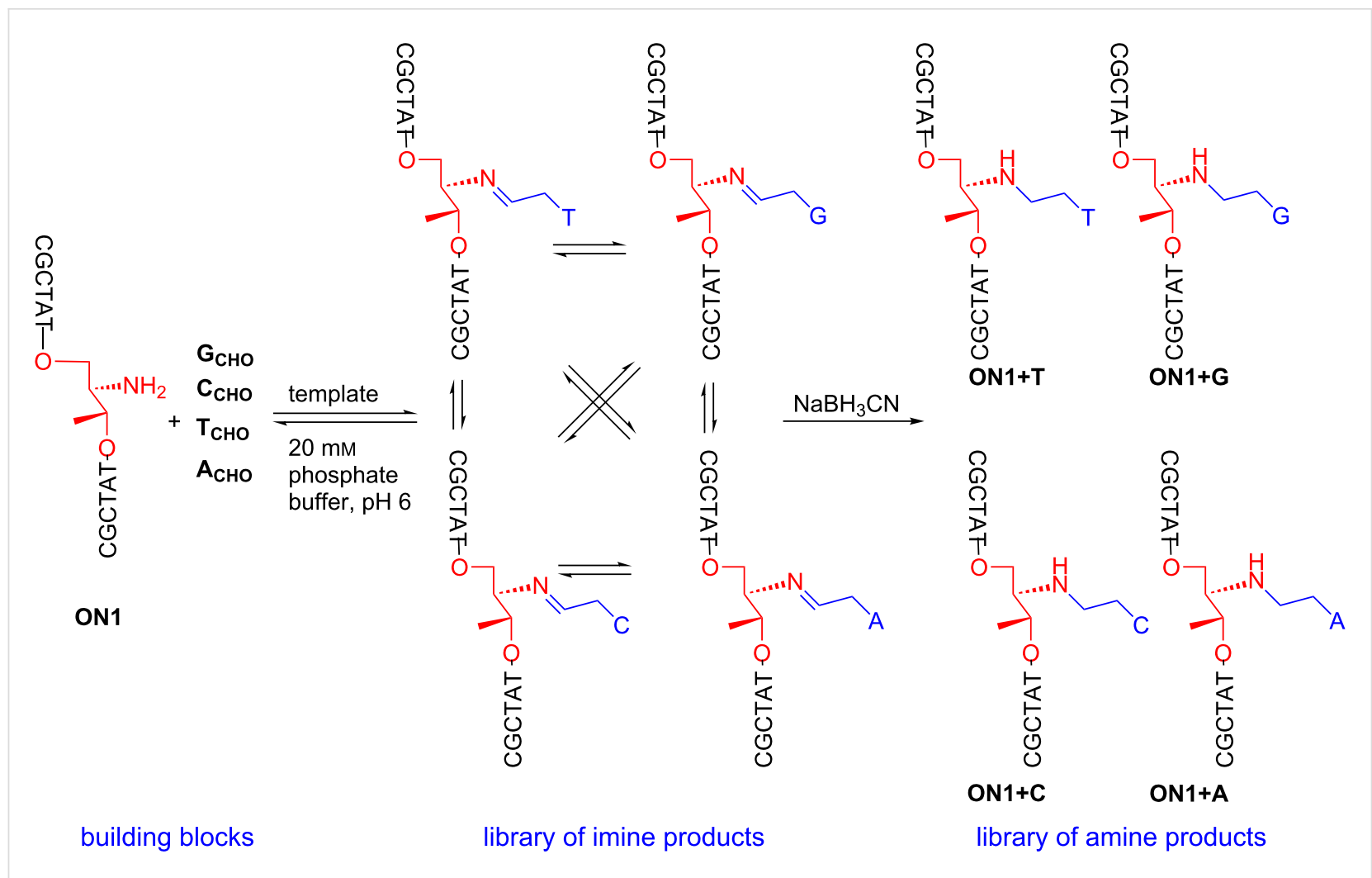

Figure 2: Initial building blocks of a dynamic combinatorial library, a library of all possible imine products and a library of amine products after reduction.<smiles>Nc1nc2c(ncn2CC=O)c(=O)[nH]1</smiles>

$\mathrm{G}_{\mathrm{CHO}}$<smiles>Nc1ccn(CC=O)c(=O)n1</smiles>

$\mathrm{C}_{\mathrm{CHO}}$<smiles>Nc1ncnc2c1ncn2CC=O</smiles>

$\mathbf{A}_{\mathrm{CHO}}$<smiles>Cc1cn(CC=O)c(=O)[nH]c1=O</smiles>

$\mathrm{T}_{\mathrm{CHO}}$

Figure 3: Set of aldehyde-modified nucleobases used in dynamic chemistry assay.

isolation and analysis of the library derived from oligonucleotide ON1. Anion exchange high-performance chromatography was used for the analysis of the final reaction mixture. The reaction mixtures were composed of six oligonucleotides: the unreacted initial strand $\mathbf{O N 1}$, one of its complementary strands $\mathbf{T}_{\mathbf{C}}$, $\mathbf{T}_{\mathbf{G}}, \mathbf{T}_{\mathbf{T}}$ or $\mathbf{T}_{\mathbf{A}}$ and the four possible product strands $\mathbf{O N} \mathbf{1}+\mathbf{G}$, ON1+C, ON1+A, ON1+T (Figure 4). HPLC separation of the four possible products in the same reaction mixture was challenging because the lengths of the starting sequence CGCTATXTATCGC (ON1) and the product sequences $(\mathrm{ON} 1+\mathrm{G}, \mathrm{ON} 1+\mathrm{C}, \mathrm{ON} 1+\mathrm{A}, \mathrm{ON} 1+\mathrm{T})$ were identical differing only by one nucleobase in the central position $\mathbf{X}$. As shown in
Figure 4 all possible products were eluted as a mixture separated by anion exchange HPLC at $80{ }^{\circ} \mathrm{C}$; under these conditions dissociation of obtained oligonucleotide double strands is provided. Well separated signals correspond to the temple strands and starting oligonucleotide ON1. The obtained four new strands $(\mathbf{O N 1}+\mathbf{C}, \mathbf{O N 1}+\mathbf{G}, \mathbf{O N 1}+\mathbf{T}, \mathbf{O N 1}+\mathrm{A})$ were eluted with similar retention time and broad elution profiles. Therefore, the product containing fractions were subjected to a second HPLC purification step applying basic conditions ( $\mathrm{pH} 12)$ to separate these compounds (Figure 5). At high $\mathrm{pH}$ deprotonation of guanine and thymine allow better separation. As indicated by the elution profiles in Figure 5, the template strands significant- 
a)

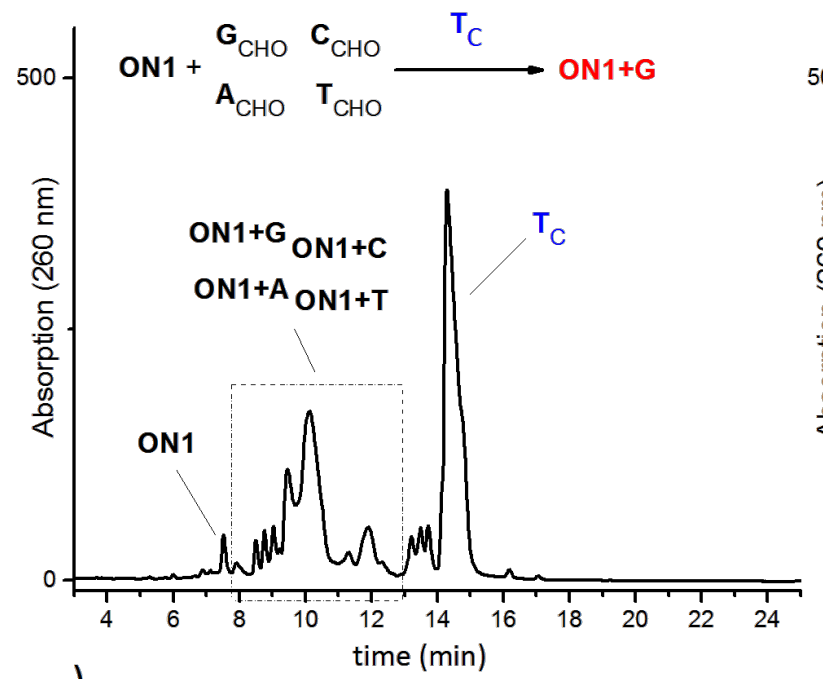

c)

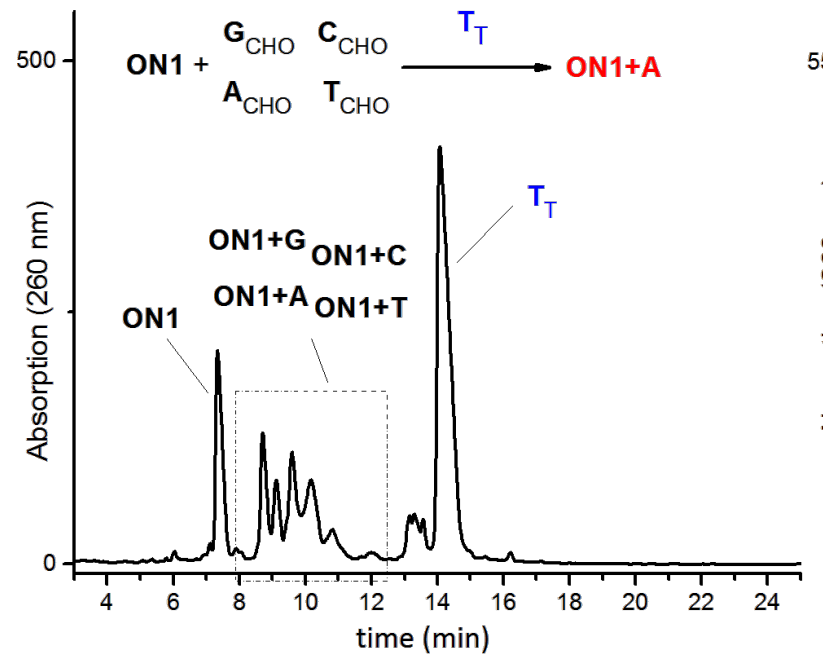

b)

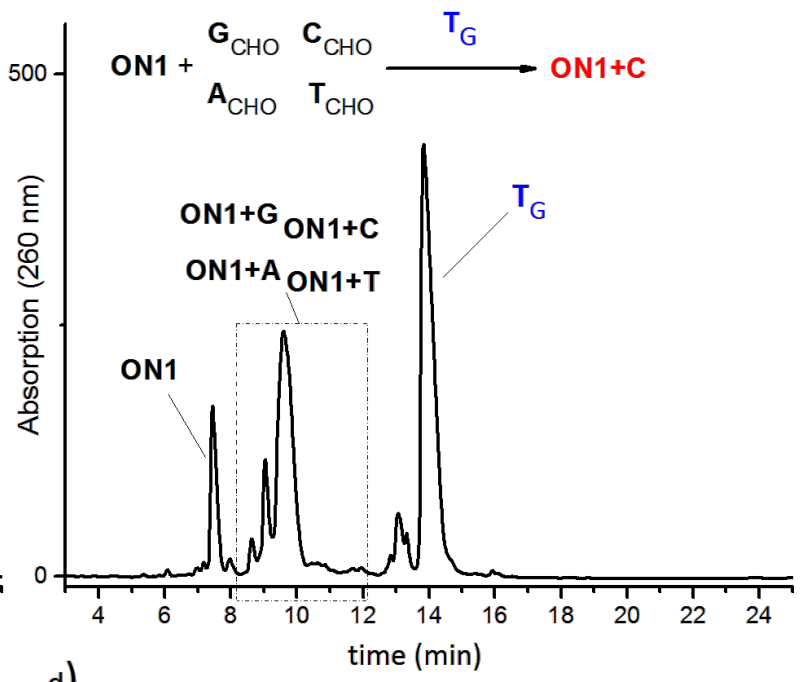

d)

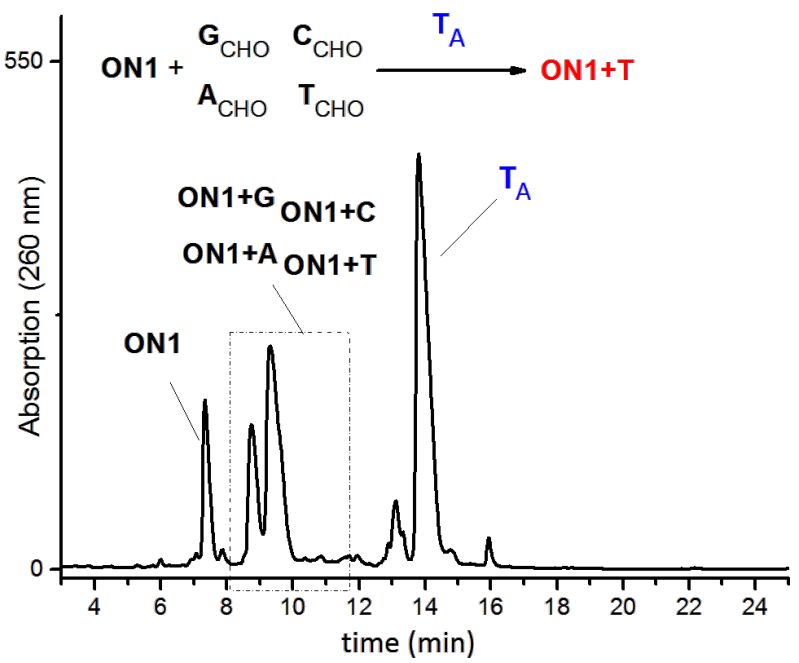

Figure 4: Representative HPLC chromatograms for the mixture containing ON1 and four nucleobases in the presence of a DNA-template: a) $\mathrm{T}_{\mathbf{C}}$; b) $\mathbf{T}_{\mathbf{G}}$; c) $\mathbf{T}_{\mathbf{T}}$; d) $\mathbf{T}_{\mathbf{A}}$. The chromatograms were performed after reductive amination of the samples (for more details see Supporting Information File 1 ).

ly affect the composition of the dynamic library. The control experiment lacking the template provided a nearly equal distribution of oligonucleotides (results are not given here).

The highest selectivity of more than $80 \%$ was obtained for the incorporation of $\mathbf{G}_{\mathbf{C H O}}$ (Figure 5a) with the complementary template strand $\left(\mathbf{T}_{\mathbf{C}}\right)$. The Watson-Crick base-pairing with three hydrogen bonds together with a high-stacking contribution of purine nucleobases seems to be beneficial. The selectivity for the incorporation of the other aldehydes is significantly lower (20-40\%). Especially for $\mathbf{C}_{\mathbf{C H O}}$ with the complementary guanine $\left(\mathbf{T}_{\mathbf{G}}\right)$ template nucleobase incorporation was not supported by Watson-Crick $\mathbf{G} \cdot \mathbf{C}$ base-pairing (Figure 5 b). The templating reactions were repeated four times applying differ- ent HPLC conditions. In all cases, incorporation of $\mathbf{G}_{\mathbf{C H O}}$ in the presence of template $\mathbf{T}_{\mathbf{C}}$ was obtained with clear preference.

In case of incorporation of the thymine aldehyde the $\mathbf{T}_{\mathbf{A}}$ containing template was not effective by supporting the expected ON1+T product as it would have been supported by the $\mathbf{A} \cdot \mathbf{T}$ base pair formation (Figure 5d). Moreover, this dynamic library is even dominated by the two $\mathbf{A} \cdot \mathbf{C}$ and $\mathbf{A} \cdot \mathbf{G}$ mismatches indicating a highly flexible arrangement of the incoming nucleobases. In general, the low template directed selectivity for incorporation of individual nucleobases is likely due to the higher flexibility in the backbone derived from threoninol units. The canonical Watson-Crick $\mathbf{A} \cdot \mathbf{T}$ and $\mathbf{C} \cdot \mathbf{G}$ base pairs are most energetically favorable, while other purine-purine (like $\mathbf{A} \cdot \mathbf{A}, \mathbf{G} \cdot \mathbf{G}$ ) 


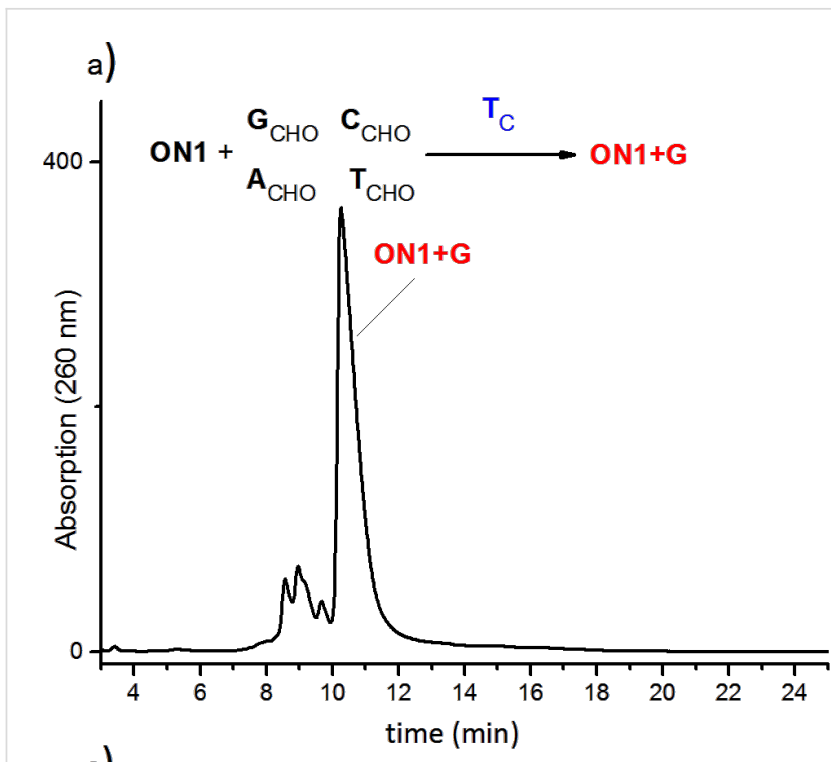

c)
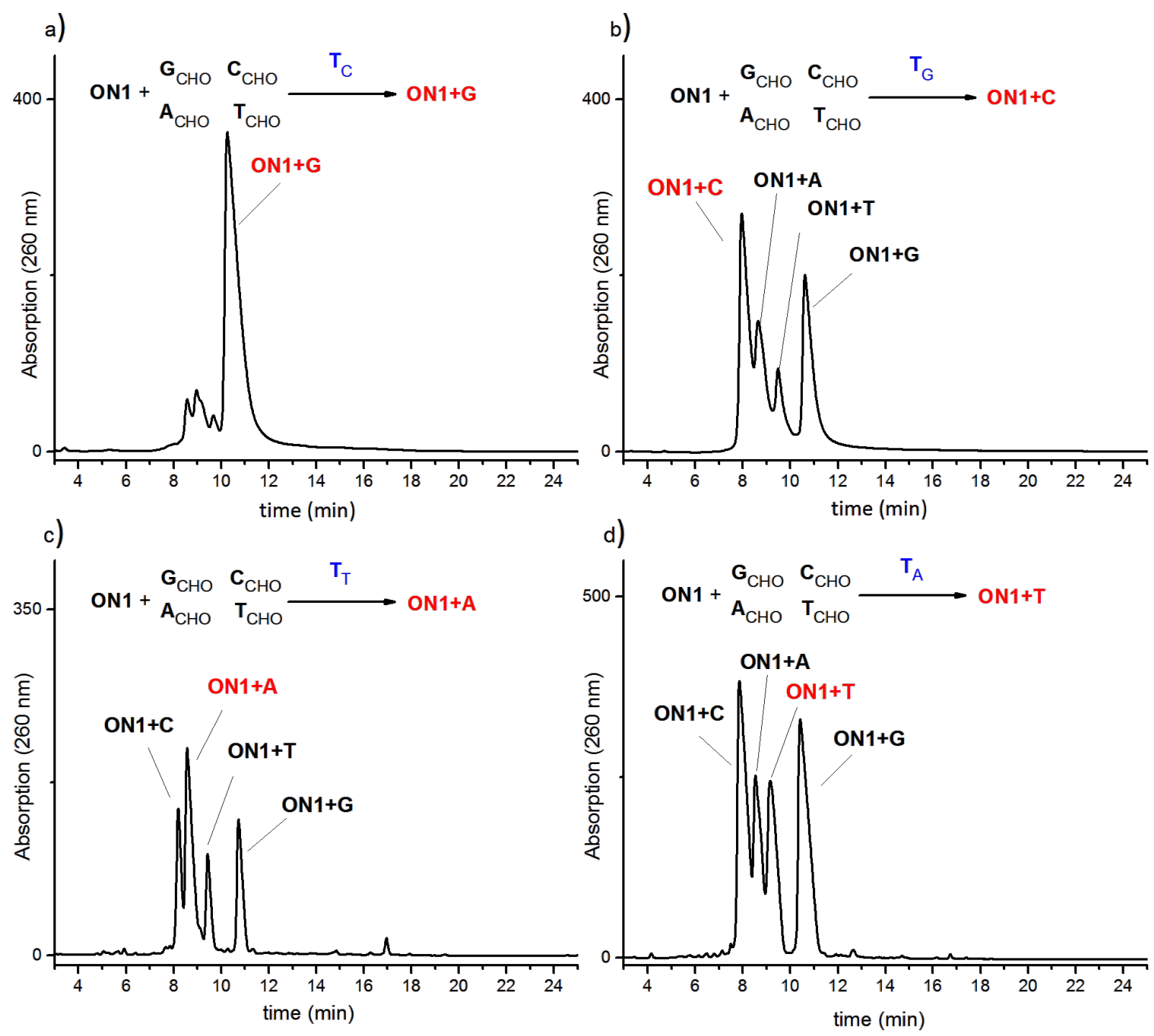

Figure 5: Representative HPLC chromatograms obtained using elevated $\mathrm{pH}$, for samples collected from first purification step (in Figure 4 marked with dashed line). The samples were collected from the reaction of ON1 and four nucleobases in the presence of a DNA-template: a) $\mathbf{T}_{\mathbf{C}}$; b) $\mathbf{T}_{\mathbf{G}}$; c) $\mathbf{T}_{\mathbf{T}}$; d) $\mathbf{T}_{\mathbf{A}}$. The chromatograms were obtained after reductive amination of the samples (for more details see Supporting Information File 1).

mismatches are less frequent than $\mathbf{T} \cdot \mathbf{G}$ and $\mathbf{C} \cdot \mathbf{A}$ ones. These results indicate that the selectivity of base pairing is not only driven by the number and strength of hydrogen bonds formed between two bases, but also by the backbone plasticity providing the frame for this interaction.

\section{Conclusion}

The efficient synthesis and DNA incorporation of two D-threoninol based phosphoramidite building blocks with orthogonally protected amine or thiol functional groups was described. Therefore, DNA analogues were presented that can be covalently functionalized by imine or thioester formation. In principle this concept allows dynamic DNA functionalization with all kind of functional or recognition units at positions that were modified with the threoninol deoxyribose analogous by solid phase synthesis. As proof of principle the 13mer oligonucleotide containing a threoninol derived amine functionality was submitted to dynamic combinatorial library (DCL) studies for DNA template directed nucleobase incorporation. Whereas a significant preference for the incorporation of the guanine unit directed by a complementary cytosine was found, linkage of the other nucleobases was not at all selective and it seems likely that the high flexibility of the threoninol as a deoxyribose analogue does not allow better selection. Due to difficulties in deprotection of the thiol group, oligonucleotides with threoninol derived thiol functionality are still under investigation as well as the simultaneous functionalization of DNA oligonucleotides at various positions with different kind of functional units. 


\section{Supporting Information}

\section{Supporting Information File 1}

Experimental procedures and NMR spectra of compounds

6, 7, 9-11 as well as preparation and analytical data of oligonucleotides ON1, ON2, ON1+G, ON1+C, ON1+A and ON1+T.

[http://www.beilstein-journals.org/bjoc/content/ supplementary/1860-5397-12-203-S1.pdf]

\section{Acknowledgements}

Support from the State of Lower Saxony (International Ph.D. program Catalysis for Sustainable Synthesis, CaSuS) is gratefully acknowledged.

\section{References}

1. Seeman, N. C. Nature 2003, 421, 427-431. doi:10.1038/nature01406

2. Silverman, S. K. Angew. Chem., Int. Ed. 2010, 49, 7180-7201. doi:10.1002/anie.200906345

3. Yanming, F.; Dongdong, Z.; Chao, J.; Jin, Y.; Zhang, Z.; Liu, H.; Li, D.; Ma, H.; Huang, Q.; Gothelf, K. V.; Fan, C. J. Am. Chem. Soc. 2013, 135, 696-702. doi:10.1021/ja3076692

4. Liu, M.; Fu, J.; Hejesen, C.; Yang, Y.; Woodbury, N. W.; Gothelf, K.; Liu, Y.; Yan, H. Nat. Commun. 2013, 4, No. 2127. doi:10.1038/ncomms3127

5. Ke, Y.; Voigt, N. V.; Gothelf, K. V.; Shih, W. M. J. Am. Chem. Soc. 2012, 134, 1770-1774. doi:10.1021/ja209719k

6. Knudsen, J. B.; Liu, L.; Kodal, A. L. B.; Madsen, M.; Li, Q.; Song, J.; Woehrstein, J. B.; Wickham, S. F. J.; Strauss, M. T.; Schueder, F.; Vinther, J.; Krissanaprasit, A.; Gudnason, D.; Smith, A. A. A.; Ogaki, R.; Zelikin, A. N.; Besenbacher, F.; Birkedal, V.; Yin, P.; Shih, W. M.; Jungmann, R.; Dong, M.; Gothelf, K. V. Nat. Nanotechnol. 2015, 10, 892-898. doi:10.1038/nnano.2015.190

7. Kiviaho, J. K.; Linko, V.; Ora, A.; Tiainen, T.; Järvihaavisto, E.; Mikkilä, J.; Nonappa, H. T.; Kostiainen, M. A. Nanoscale 2016, 8, 11674-11680. doi:10.1039/C5NR08355A

8. Fu, J.; Liu, M.; Liu, Y.; Yan, H. Acc. Chem. Res. 2012, 8, 1215-1226. doi:10.1021/ar200295q

9. Pinheiro, A. V.; Han, D.; Shih, W. M.; Yan, H. Nat. Nanotechnol. 2011, 6, 763-772. doi:10.1038/nnano.2011.187

10. Cobb, A. J. A. Org. Biomol. Chem. 2007, 5, 3260-3275. doi:10.1039/b709797m

11. Weisbrod, S. H.; Marx, A. Chem. Commun. 2008, 5675-5685. doi:10.1039/b809528k

12. Graham, D.; Grondin, A.; McHugh, C.; Fruk, L.; Smith, W. E. Tetrahedron Lett. 2002, 43, 4785-4788. doi:10.1016/S0040-4039(02)00930-9

13. Amblard, F.; Cho, J. H.; Schinazi, R. F. Chem. Rev. 2009, 109, 4207-4220. doi:10.1021/cr9001462

14. Fujii, T.; Kashida, H.; Asanuma, H. Nucleic Acids Symp. Ser. 2008, 52, 699-700. doi:10.1093/nass/nrn353

15. Vaquero-Vara, V.; Zhang, D.; Dian, B. C.; Pratt, D. W.; Zwier, T. S. J. Phys. Chem. A 2014, 118, 7267-7273. doi:10.1021/jp410859n

16. Aviñó, A.; Mazzini, S.; Ferreira, R.; Eritja, R. Bioorg. Med. Chem. 2010, 18, 7348-7356. doi:10.1016/j.bmc.2010.09.023
17. Takarada, T.; Tamaru, D.; Liang, X.; Asanuma, H.; Komiyama, M. Chem. Lett. 2001, 30, 732-733. doi:10.1246/cl.2001.732

18. Pérez-Rentero, S.; Grijalvo, S.; Ferreira, R.; Eritja, R. Molecules 2012, 17, 10026-10045. doi:10.3390/molecules170910026

19. Fujii, T.; Kashida, H.; Asanuma, H. Chem. - Eur. J. 2009, 15, 10092-10102. doi:10.1002/chem.200900962

20. Fukui, K.; Morimoto, M.; Segawa, H.; Tanaka, K.; Shimidzu, T. Bioconjugate Chem. 1996, 7, 349-355. doi:10.1021/bc960019k

21. Shi, Y.; Machida, K.; Kuzuya, A.; Komiyama, M. Bioconjugate Chem. 2005, 16, 306-311. doi:10.1021/bc049698m

22. Murayama, K.; Tanaka, Y.; Toda, T.; Kashida, H.; Asanuma, H. Chem. - Eur. J. 2013, 19, 14151-14158. doi:10.1002/chem.201301578

23. Asanuma, H.; Toda, T.; Murayama, K.; Liang, X.; Kashida, H. J. Am. Chem. Soc. 2010, 132, 14702-14703. doi:10.1021/ja105539u

24. Kashida, H.; Murayama, K.; Toda, T.; Liang, X.; Asanuma, H. Collect. Symp. Ser. 2011, 12, 116-124. doi:10.1135/css201112116

25. Asanuma, H.; Hara, Y.; Noguchi, A.; Sano, K.; Kashida, H. Tetrahedron Lett. 2008, 49, 5144-5146. doi:10.1016/j.tetlet.2008.06.090

26. Kashida, H.; Fujii, T.; Asanuma, H. Org. Biomol. Chem. 2008, 6, 2892-2899. doi:10.1039/b806406g

27. Kashida, H.; Liang, X.; Asanuma, H. Curr. Org. Chem. 2009, 13, 1065-1084. doi:10.2174/138527209788680736

28. Kumar, V.; Gothelf, K. V. Org. Biomol. Chem. 2016, 14, 1540-1544. doi:10.1039/C5OB02525G

29. Otto, S.; Furlan, R. L. E.; Sanders, J. K. M. Drug Discovery Today 2002, 7 (Suppl. 2), 117-125. doi:10.1016/S1359-6446(02)00006-5

30. Huc, I.; Nguyen, R. Comb. Chem. High Throughput Screening 2001, 4, 53-74. doi:10.2174/1386207013331273

31. Rowan, S. J.; Cantrill, S. J.; Cousins, G. R. L.; Sanders, J. K. M.; Stoddart, J. F. Angew. Chem., Int. Ed. 2002, 41, 898-952. doi:10.1002/1521-3773(20020315)41:6<898::AID-ANIE898>3.0.CO;2E

32. Herrmann, A. Chem. Soc. Rev. 2014, 43, 1899-1933. doi:10.1039/C3CS60336A

33. Miller, B. L., Ed. Dynamic Combinatorial Chemistry: In Drug Discovery, Bioorganic Chemistry, and Materials Science; John Wiley \& Sons: Hoboken, NJ, U.S.A., 2009. doi:10.1002/9780470551554

34. Lehn, J.-M. Chem. - Eur. J. 1999, 5, 2455-2463. doi:10.1002/(SICI)1521-3765(19990903)5:9<2455::AID-CHEM2455>3. $0 . \mathrm{CO} ; 2-\mathrm{H}$

35. Huc, I.; Lehn, J.-M. Proc. Natl. Acad. Sci. U. S. A. 1997, 94, 2106-2110. doi:10.1073/pnas.94.6.2106

36. De Stefano, M.; Gothelf, K. V. ChemBioChem 2016, 17, 1122-1126. doi:10.1002/cbic.201600076

37. Hansen, D. J.; Manuguerra, I.; Kjelstrup, M. B.; Gothelf, V. K. Angew. Chem., Int. Ed. 2014, 53, 14415-14418. doi:10.1002/anie.201405761

38. Lehn, J.-M. Angew. Chem., Int. Ed. 2015, 54, 3276-3289. doi:10.1002/anie.201409399

39. Reddavide, F. V.; Lin, W.; Lehnert, S.; Zhang, Y. Angew. Chem., Int. Ed. 2015, 27, 7924-7928. doi:10.1002/anie.201501775

40. Lin, J.; Surin, M.; Beljonne, D.; Lou, X.; van Dongen, J. L. J.; Schenning, A. P. H. J. Chem. Sci. 2012, 3, 2732-2736. doi:10.1039/c2sc20389h

41. Diederichsen, U. ChemBioChem 2009, 10, 2717-2719. doi:10.1002/cbic. 200900543

42. Ura, Y.; Beierle, J. M.; Leman, L. J.; Orgel, L. E.; Ghadiri, M. R. Science 2009, 325, 73-77. doi:10.1126/science.1174577 
43. Bowler, F. R.; Diaz-Mochon, J. J.; Swift, M. D.; Bradley, M. Angew. Chem., Int. Ed. 2010, 49, 1809-1812. doi:10.1002/anie.200905699

44. Heemstra, J. M.; Liu, D. R. J. Am. Chem. Soc. 2009, 131, 11347-11349. doi:10.1021/ja904712t

45. Zhan, Z.-Y. J.; Lynn, D. G. J. Am. Chem. Soc. 1997, 119, 12420-12421. doi:10.1021/ja972870v

46. Li, X.; Liu, D. R. Angew. Chem., Int. Ed. 2004, 43, 4848-4870. doi:10.1002/anie.200400656

47. Meyer, C. D.; Joiner, C. S.; Stoddart, J. F. Chem. Soc. Rev. 2007, 36, 1705-1723. doi:10.1039/b513441m

48. Bierer, D. E.; Dener, J. M.; Dubenko, L. G.; Gerber, R. E.; Litvak, J.; Peterli, S.; Peterli-Roth, P.; Truong, T. V.; Mao, G.; Bauer, B. E. J. Med. Chem. 1995, 38, 2628-2648. doi:10.1021/jm00014a016

49. Coleman, R. S.; Siedlecki, J. M. J. Am. Chem. Soc. 1992, 114, 9229-9230. doi:10.1021/ja00049a089

50. Miller, G. P.; Silverman, A. P.; Kool, E. T. Bioorg. Med. Chem. 2008, 16, 56-64. doi:10.1016/j.bmc.2007.04.051

51. Jarowicki, K.; Kocienski, P. J. Chem. Soc., Perkin Trans. 11998, 4005-4037. doi:10.1039/a803688h

52. Jarowicki, K.; Kocienski, P. J. Chem. Soc., Perkin Trans. 12001 , 2109-2135. doi:10.1039/b103282h

53. McGregor, A.; Vaman Rao, M.; Duckworth, G.; Stockley, P. G.; Connolly, B. A. Nucleic Acids Res. 1996, 24, 3173-3180. doi:10.1093/nar/24.16.3173

54. Hamm, M. L.; Cholera, R.; Hoey, C. L.; Gill, T. J. Org. Lett. 2004, 6, 3817-3820. doi:10.1021/ol0484097

55. Hamm, M. L.; Piccirilli, J. A. J. Org. Chem. 1997, 62, 3415-3420. doi:10.1021/jo970096o

56. Chambert, S.; Gautier-Luneau, I.; Fontecave, M.; Décout, J.-L. J. Org. Chem. 2000, 65, 249-253. doi:10.1021/jo9908492

57. Bornemann, B.; Liu, S.-P.; Erbe, A.; Scheer, E.; Marx, A. ChemPhysChem 2008, 9, 1241-1244. doi:10.1002/cphc.200800081

58. Chambert, S.; Désiré, J.; Décout, J.-L. Synthesis 2002, 2319-2334. doi:10.1055/s-2002-35231

59. Doel, M. T.; Jones, A. S.; Taylor, N. Tetrahedron Lett. 1969, 10 , 2285-2288. doi:10.1016/S0040-4039(01)88143-0

60. Doláková, P.; Masojídková, M.; Holý, A. Nucleosides, Nucleotides Nucleic Acids 2003, 22, 2145-2160. doi:10.1081/NCN-120026636

61. Li, W.; Li, J.; Wu, Y.; Fuller, N.; Markus, M. A. J. Org. Chem. 2010, 75, 1077-1086. doi:10.1021/jo902014z

\section{License and Terms}

This is an Open Access article under the terms of the Creative Commons Attribution License

(http://creativecommons.org/licenses/by/4.0), which permits unrestricted use, distribution, and reproduction in any medium, provided the original work is properly cited.

The license is subject to the Beilstein Journal of Organic Chemistry terms and conditions:

(http://www.beilstein-journals.org/bjoc)

The definitive version of this article is the electronic one which can be found at:

doi:10.3762/bjoc. 12.203 